\title{
Coronavirus Pandemic: Fear of the Unknown, Shaking Psychological Well-being, Economy, Politics and Morality
}

\author{
Mogobe Ben Ramose \\ https://orcid.org/0000-0003-3921-7613 \\ Sefako Makgatho Health Sciences (SMU) \\ proframose@outlook.com
}

\author{
Molelekeng Sethuntsa \\ https://orcid.org/0000-0002-4096 \\ Sefako Makgatho Health Sciences (SMU) \\ Tembisa Provincial Tertiary Hospital \\ molelekeng.sethuntsa@gmail.com
}

\section{Abstract}

The essay examines the meaning and impact of Covid-19 in comparative relation to some of the experiences of the Black Death (1348-1350). It also presents and critically analyses actual case studies of pseudo-named people - in recognition and respect for confidentiality in research ethics-infected by Covid-19. "South Africa" is the primary but not the only focus of this essay. The thesis defended in this essay is that the "social distance" prescribed as a preventative measure to curb the spread of Covid-19 ought to be complemented by ethical "proximity to the other."

Kweli phepha, sizo bonakalisa iintlungu eziviwe ngabantu abaye basuleleka yintsholongwane ye Corona-iSevere Acute Respiratory Syndrome Coronavirus 2 (Covid-19) ngelasemzini. Lentsholongwane ibaphazamise ngokwase moyeni nangokwase ngqondweni. Sizo phinda sijonge ukuba iCorona ingathelekiswa njani nokuba yohluke njani kwi medieval Black Death eyabulala abantu abaninzi mandulo. Abantu aba balisa amabali abo kweli phepha baphiwe amagama angewo wenyani ukuze sibahloniphe, nemfihlo zabo zingafikeleli kubantu ababaziyo.

Keywords: Covid-19; Black Death; dogmatism; psychological impact; morality; stigma; social distance; traditional medicine

\section{Introduction}

It is trite to mention that humanity has known and lived through pandemics before the eruption of the Severe Acute Respiratory Syndrome Coronavirus (Covid-19). From the past experiences of pandemics this essay selects the "Black Death," the "Great

\section{UNISA $\cong$}


Mortality," the "Plague" or the "Pestilence" as its point of departure. Historians differ on the commencement and duration of the "Black Death." Some date it as 1348-1349 (Cantor 2002, 5-7) while others fix it at 1348-1350 (Langer 1975, 319).

We have selected the Black Death for the following reasons. One pertains to the literal meaning of "black" as the absence, whole or partial, of light. In this sense, black is akin to darkness. German philosopher Georg Hegel used this meaning of darkness to describe Africa as without history, whereas Polish literary writer Joseph Conrad also used it to describe Africa in his novel, the "Heart of Darkness." The use of black or blackness in this way is metaphorical. We will also use the metaphorical meaning of black without endorsing or adopting the specific meanings that Hegel and Conrad attached to it.

Another reason is to complement the literal meaning of black by its metaphorical meaning. The latter refers to the active search for knowledge in order to overcome ignorance. It is also used to denote "black" people, that is to say, human beings identifiable by their shared experience of subjugation, expropriation, oppression and exploitation since the unjust wars of colonisation. The master-slave relationship that went hand-in-hand with the unjust wars of colonisation was predicated on the fallacy that blacks were slaves by nature and were destined to perpetual imbecile childishness or puerility. As such, they were deemed to be irresponsible, incapable of knowing what is good for them, and unable to see danger. This meaning subsists despite constitutional affirmations in many countries that all human beings are equal and must, therefore, be recognised as "equal before the law." Our argument in this connection is that the health of the people is the supreme law that ought to underlie any constitution. Contemporary practice has, however, subverted this supreme law by conceding to a constitutional dispensation making the right to health an optional instead of an obligatory duty of the state. In this way, practice undermines the principle of "equal before the law" because access to adequate and efficient health care becomes restricted to the wealthy. Such a situation may properly be described as "the Black Death." We recognise, however, that the Black Death does not necessarily have these metaphorical connotations because "it got its name from dark blotches produced by haemorrhages in the skin" (Langer 1975, 319).

\section{Thesis}

The thesis defended here is that the sudden eruption of Covid-19 caused the fear of the unknown across the globe. It gave rise to either conformist or conflicting behaviour on the one hand and, laid bare by greater intensity, the sharp contrast between economic affluence and historical structural poverty. It exposed the widening gap between intellectual poverty and epistemological wealth. Our argument is that the proper understanding of this fear ought to lead to the recognition that the "social distance" prescribed as a preventive measure to diminish the spread of Covid-19 must be complemented by the ethical exigency of proximity to the other. 


\section{Approach}

Our approach to the elaboration of the above thesis is to compare and contrast the experiences of the Black Death with those that occurred in "South Africa" since the eruption of Covid-19 until the time of the writing of this essay. The latter category of experiences includes those that are direct personal observation and those that appear in the form of specific cases. It is to be noted with emphasis that the names of persons, places or institutions mentioned in the case studies are all fictitious. Should any name of a person or institution be similar to anyone known alive or dead this is pure coincidence. Coincidence also applies to the names of places.

The cases presented are themselves not fictions. They are true stories of people who shall remain anonymous in compliance with the principle of confidentiality in research ethics. "Research" under the extraordinary situation brought about by the eruption of Covid-19 cannot assume its normal ordinary meaning. Information that could possibly lead to their identification will be excluded. The participants gave their informed consent for the information to be shared. Two of the participants shared their experiences telephonically, one sent an audio recording, and three sent written memos of their experiences. Our concern is with the psychological and social aspects and not the medical aspects of Covid-19. However, we will refer to medical issues whenever it is necessary.

\section{Contrasts and Comparisons}

In answer to the question: "Where did the Black Death start?" we read that "One account was that the pandemic began with climatic disasters and [an] earthquake in China, causing floods, from which came disease that moved westward" (Cantor 2002, 17). It is interesting that "China" is mentioned as the place where the Black Death "began." With regard to the origin of Covid-19, the finger once again points at China, as stated below.

The Severe Acute Respiratory Syndrome Coronavirus (Covid-19) also originated in Wuhan, China, towards the end of 2019. The outbreak spread rapidly around the world in a matter of months and has had a significant impact on our lives. The first confirmed case in "South Africa" was announced on 5 March 2020, and the first death was reported on 27 March. At first, the cases were far in between and the morbidity rate remained low. However, since then the number of positive cases has increased significantly and the mortality rate has also increased. As of 29 August, the total number of confirmed positive cases in "South Africa" was 622 551; the total number of deaths was 13981; and the total number of recoveries was 536 694, which meant a recovery rate of $86 \%$. The number of tests conducted both in public and private facilities was 3652970 (Mkhize 2020a).

The medieval physicians at the time of the Black Death were caught off guard and could not provide any effective preventive or curative medicine for the disease (Cantor 2002, 23; Langer 1975, 320). This is comparable to the eruption of Covid-19, which caught 
the medical profession unprepared to deal with it effectively. The fear and the scare around Covid-19 diminished to some extent, as the will and courage of the medical profession to deal with it, became apparent. Dying in the cause of helping others regain their health - physical, intellectual and spiritual — is a decision that is not available to everyone inside or outside the medical profession.

Here it is important to reflect upon the life of Jozef de Veuster, born on 3 January, 1840 in Tremelo, Belgium. He later chose the name, Damien, and came to be known as Pater (Father) Damien, member of the Congregation of the Sacred Hearts or Picpus Fathers. He worked as a Roman Catholic missionary in Hawaii and later moved to the Kolawao leper colony on Molokai island. At that time there was no reliable and effective cure for the leprosy pandemic. Kolawao was chosen because it was a suitable place to quarantine the sick. There Pater Damien became the leper among lepers. When he realised that he would die of leprosy, he insisted on dying among the lepers. He wrote from Kolawao in 1889 to the Reverend H. B. Chapman thus: "There is scarcely a glimmer of hope that I will recover ... unless by a miracle. But I would not even ask the Lord for one, convinced as I am that it is His holy Will that I should die in the same manner and of the same sickness as my infected sheep" (Congregation of the Sacred, n.a.).

Research aiming to find a cure is on-going, despite the claim by other countries that they have already found either a "cure" or a vaccine for Covid-19. In the domain of research, the race to be "the first" to discover a cure is intensifying in many ways. One of the reasons for the intensification of the race is the prospect of claiming the copyright to the cure. This is hardly surprising, if one recalls the struggle to be "the first" to have identified and isolated the HIV (Fan, Conner, and Villarreal 1994, 3 and 106) between the French research team into HIV/AIDS led by Luc Montaigner of the Pasteur Institute, and the United States of America research team in the same field led by Robert C. Gallo of the Laboratory of Tumor Cell Biology at the National Cancer Institute in Bethesda, Maryland. The struggle ultimately involved the then President of the United States, Ronal Reagan and the French Prime Minister Jacques Chirac. It was ended through the signing of the 1987 "Settlement" between the United States and the Pasteur Institute (Palca 1987). The core of the Settlement was that both parties agreed that HIV was discovered at the same time by the two separate research teams (New Scientist 1987).

The race to be "the first" is an illustration of the prevalence of pecunimania in our time; an insatiable and irrational resolution to accumulate money at any cost. It is the manifestation of the sovereignty of money which puts wealth before human wellbeing - in this case, particularly, health. In his De Legibus, book III, part III, sub. VIII, Cicero wrote that "salus populi, suprema lex esto." The various translations of this maxim do not deviate from the basic insight that the health of the people shall be the supreme law. It is significant that Cicero makes this jussive declaration under the important title, "On Laws." Whatever laws there may be in a given human community, they ought to recognise, respect, protect and promote the foundation upon which they are built, namely, the health or well-being of all the individuals constituting the 
community. Yet, contemporary Western legal philosophy appears to have obliterated Cicero's ethical maxim from the archive of its memory by allowing the "Third World health" to be held "hostage to First World wealth" (MacDonald, 2005). This is a plunge into the Black Death; a wilful but irrational death wish. There is no need to wish for death because it is the inevitable destiny of all that lives, including the sun.

Politicians were also caught off guard by the tremor of the eruption of Covid-19. It shook politics into swift and not always sober action. The action undermined economic activity, especially in its demand on the economy to accept that sharing the bread from Mother Earth is the command of "social distance" prescribed by Covid-19. This command of ethical proximity to the other should have been the easiest to obey in light of the declaration by former President of the United States of America, John F Kennedy, almost sixty years ago that: "The world is different now. For man holds in his mortal hands the power to abolish all forms of human poverty and all forms of human life" (Kennedy inaugural speech 20 January, 1961).

Today we may be puzzled by Kennedy's reference to "man," as though there were no women in his lifetime. This might be a habitual adoption of Aristotle's submission that "man is a rational animal"; as if he was not born of a woman. The repercussions of Aristotle's definition still live with us at least in two ways. One is the restrictive interpretation of his averment favouring only a segment of the human family, placing it at the apex of an imaginary - though in their mind real — ontological hierarchy. Another is that the same restrictive interpretation was used to argue for the practical subordination of women to men.

We return to the citation from Kennedy's speech against the background of the observations in the preceding paragraphs. We suggest that "man" in that context meant human beings. And so, we pose the following question: Why then were so many across the globe - the now more than "bottom billion" of Paul Collier (2008) - still dying of "human poverty" before and during Covid-19? What had happened to "mortal man's" power to prevent and eliminate "all forms of human poverty?" In the current situation of Covid-19, the preventative measure of "social distance" has been turned into the resolute determination to reject the ethical appeal of proximity to the other.

To deny the right to exist and to reason of other human beings impoverished historically, systemically and systematically by a structure that prefers to erect "butter mountains" and dig "milk lakes"- a euphemism for excess food in the European Union to be thrown into the ocean to preserve a socioeconomic order that is "unjust at its root" and "spawns violence" (Pope Francis 2013, par 59) - is ethical obtuseness that cannot remove the fear and panic caused by Covid-19. It is to decree and promote the Black Death in the human family.

To forget that there are indeed situations in which - as Saint Thomas Aquinas argued (Shea 2018, 277-293) on God-sanctioned stealing — even God would allow stealing is 
to pour scorn over the intelligence of the poorest of the poor to defend their right to selfpreservation. The rejection of ethical proximity to the other during and beyond Covid19 is a blind dogmatic opening of the floodgates of the Black Death; an amoral situation of mortal strife among human beings.

We read that in the course of the Black Death, "Physicians attributed the plague to physiological imbalance, and when that story paled in the face of a raging pandemic, other explanations were trotted out. A commission of Parisian scholars assembled by the king soberly announced that the problem was astrological, something about Saturn in the house of Jupiter" (Cantor 2002, 119-120). The reference to the planets here is important, even though the scholars appear not to have noticed its significance. Around the same time, an Oxford scholar, Thomas Bradwardine, espoused the theory that "space was an infinite void in which God could have created other worlds" (Cantor 2002, 110). Because Bradwardine was a social conformist by temperament, he did not pursue the "revolutionary implications [of his theory]. It departed from the comforting medieval assumption that this earth was God's only created planet. It looked forward to modern recognition that there may be other worlds on which life exists. Thereby it threatened the singularity of our world and of human life and its relationship to God" (Cantor 2002, 110).

The planetary or cosmic thinking espoused by Bradwardine was subsequently reaffirmed, though not by way of a direct response to Bradwardine, in philosophy through its rejection of dogmatism and the endorsement of revolutionary thinking. Wahbah explains this by reference to what he describes as the task of "cosmic consciousness."

But this new breeding is in need of the technological and scientific revolution that will lead to the creation of a new species of man, that is, the space man or the cosmic man equipped with cosmic consciousness that will revolutionize the pattern of human thinking ... through the cosmic consciousness, creativity without stop will be the essence of man. And creativity, by its very nature, is against any dogma ... against any absolute. (Wahbah 1984, 236)

But a large segment of the scientific community during the time of Bradwardine (and now during Covid-19) tended to be sceptical about planetary or cosmic thinking. Renowned Cambridge astrophysicist, Fred Hoyle, and Applied Mathematics and Astronomy Professor Chrandra Wickramasinghe of the University of Wales, published research arguing that the cause of the Black Death could have come from outside of planet Earth. By this they did not necessarily deny all existing scientific knowledge about the Black Death. On the contrary, their argument may well be construed as a plea for the extension as well as the expansion of the scientific vision by taking into account what they described as the "vertical transmission" of the Black Death (Cantor 2002, $178-182)$. 


\section{Ramose, Sethuntsa}

In spite of Hoyle's and Wickramasinghe's impeccable scientific credentials, their thesis that the Black Death originated in cosmic dust has been totally ignored in the standard historical works on the subject. But the Hoyle thesis has gained some surprising sympathy in scientific circles. In the 1980s Sir Francis Crick ... mounted arguments similar to Hoyle's, causing a momentary press sensation. In 1999 Paul Davies, a theoretical physicist ... published The Fifth Miracle: The Search for the Origin and Meaning of Human Life, which again inclined to Hoyle's belief in interplanetary transfer of organisms, which was again on this point ignored. (Cantor 2002, 181-182)

Standard science has, in general, tended to dismiss even the relevance of lengana or umhlonyane (Artemisia afra) to the search for light leading to the cure of Covid-19. Such dogmatism, being the "scientification" of science bringing it very close to the sanctification of science, is contrary to the very meaning of science as an open-ended inquiry into truth and meaning. It is an unwarranted condemnation of humanity into the Black Death. Avoiding this death means recognising the relevance of planetary thinking in pursuit of scientific endeavour. We now turn to the situation in "South Africa" in light of the contrasts and comparisons mentioned above.

\section{The Situation in "South Africa" with Particular Reference to Case Studies}

South Africans received daily reports through the media on a sharp increase in positive cases and the rising death toll. Life was changing drastically as we knew it. It created a lot of anxiety and no one wanted to be infected with the virus. This mass fear of Covid19 (termed "coronaphobia") is likely due to the uncertain character and unpredictable course of the disease, intolerance of uncertainty, perceived risk of acquiring the infection, and the fact that Covid-19 can generate negative psychological responses, including maladaptive behaviours, emotional distress and avoidance reaction among common people (Dubey, Biswas, and Gosh et.al. 2020). The Covid-19 pandemic has become a significant psychological stressor. Fear of illness and uncertainty about the future precipitate anxiety and stress-related disorders (Troyer, Kohn, and Hong 2020). Patients with confirmed Covid-19 or those suspected to have Covid-19, experience fear of the consequences of being infected with a potentially fatal new virus (Carvalho, Moreira, and De Oliveira 2020).

Initially, the people who got infected were not known; then it moved closer to someone who knew someone; then it became someone known to the community; and then close people were also getting infected. We report on the lived experiences of Covid-19 survivors who self-isolated at home.

\section{Case 1: Lived Experience of a Clinical Psychologist: "The Psychological Battle was worse than the Physical Symptoms"}

Nthatisie is a 39-year old Sotho-speaking single black African female, with one child. She works as a clinical psychologist in a government hospital. What prompted her testing was a sore throat and nasal congestion. She recalled receiving her results through 
an SMS (short message service) from the laboratory: "I read the first line, then the second, then the second line again and again until it sunk in-it means you are infected. I felt my upper body freeze, I felt the chills. I was in shock. Tears streamed down my cheeks; I could not hold them back. The thought that I had an unknown fatal disease was enough to increase my anxiety. The uncertainty of how my body will respond to the virus was overwhelming."

She informed her manager, the OHS (Occupational Health and Safety) clinic, colleagues, family and friends. She was overwhelmed by phone calls and messages as everyone gave her advice on how to treat Covid-19 symptoms. Most people were suggesting she uses Lengana or Umhlonyane (aretemisia afra). However, the OHS doctor warned her against taking any herbal medicines as "these" may affect her kidneys and suggested she continued with the treatment she got from the doctor.

She emphasised that the psychological battle was worse than the physical symptoms. She was constantly worried about worsening symptoms and possibly needing hospitalisation. She was using bleach on dishes, utensils, and in cleaning the house and surfaces every day out of fear for the virus and fear of re-infection. She did not even consider the question of whether or not a virus can be killed. Anxiety does not always encourage serenity and systematic reasoning. She also mentioned the negative impact the diagnosis had on her son, who thought she was going to die because Covid-19 patients were dying.

She shared her disappointment that she did not receive any communication from the National Institute for Communicable Disease (NICD); her listed contacts were not traced or informed. According to the Covid-19 guidelines: "If laboratory testing confirms SARS-CoV-2 infection, the district/provincial outbreak response team will be requested to use the contact line list to call each contact" (NICD 2020, 15). She took it upon herself to inform her known contacts and also checked on them. What was strange, but also a relief for her, was that she got infected but she did not infect anyone she knew.

A couple of days later she experienced loss of smell, persistent and prolonged headache, stomach cramps, mild diarrhoea, dry skin and brittle hair, which resulted in hair loss. She reiterated that the recovery process was dependent on adopting a positive mindset. She received adequate support from her family, colleagues, patients and friends. Her mother and a close friend were the only people she permitted to bring items to her house, but they would leave them by the door and they would talk behind a closed window. However, this scene made her feel like she had leprosy; which is very interesting that she compared it to leprosy, as we indicated earlier it was one of the feared diseases.

She had to deal with ignorance from her colleagues who were blaming her for exposing them to the virus. She believes that anyone could have been walking around the office, being asymptomatic and unaware. She felt stigmatised from the moment she announced that she had tested positive for Covid-19. The process of deep cleaning and disinfecting 


\section{Ramose, Sethuntsa}

the office made her feel like she had committed a crime; she felt dirty, she felt like she was oozing the virus and was spreading it all over. When she returned to work, she was welcomed by most, but a few avoided her and shifted with fear when she walked past, and some would immediately wear their masks - these behaviours made her feel like a "walking Covid-19." Some even asked her not to tell others that she had tested positive for Covid-19 because they would be scared of her and discriminate against her.

Post isolation, she was extra cautious, she had to get a company to disinfect and fog her house and car. She was always wearing a mask and washing hands more than usual so that she sanitised. She became more observant and wary of people who were not wearing masks. She would refuse to engage with those who were not wearing masks properly. She considered herself lucky that she had survived but sometimes experienced survival guilt when providing psychotherapy to bereaved families whose family members had died from Covid-19 complications.

\section{Case 2: Lived Experience of a Professional Nurse: "I was Anxious"}

Wongeka is a 34-year old, Zulu-speaking black African married female with three children. She works as a nurse in a public hospital. Wongeka was infected in the line of duty by a patient, when they were not offered proper personal protective equipment (PPE). The hospital management was more concerned about patients being infected instead of the nurses and they felt blamed by the management. Wongeka reported experiencing a strange flu compared to the normal one. She presented with cough, chest pains, headaches, dizzy spells, diarrhoea, loss of smell, poor appetite, loss of taste, body pains and body chills.

Her husband, who is also a nurse, was also a close contact of a colleague that had tested positive for Covid-19 and he also tested positive. He got his results before she got hers. "It was the first time in my life seeing my husband crying." He had a cough, throat irritation, tiredness and he was mostly scared. They decided that he would isolate at home. A couple of days later she and the children tested positive for Covid-19. "I felt that something inside me just died, the tears were just rolling down my eyes. I couldn't speak ... the thought of being the first of 20 staff members that tested positive in the hospital was so scary and frustrating." In addition to the medication she received from the doctor, she was using Umhlonyane and White Gum tree that were prescribed by her father, who is a traditional healer. She did not consume them but used them to steam.

Two weeks later the first born's results were still positive, but she had to go back to school in a semi-urban area. The school demanded negative results before accepting her back. She also had to deal with negative comments from the community, from other learners and teachers. She had to attend psychotherapy to cope. She reported feeling guilty because she believed she had infected her family, despite the knowledge of how her husband got infected. On day 13, she reported, her symptoms got worse and she had a strong fear of dying but she refused admission. She was also experiencing anxiety, panic attacks, hearing loss and hair loss. She contacted her psychologist for intervention. 
On day 15 her results were still positive but she was told to resume duties by the OHS doctor. She felt pressured by the employer to go back to work, even though she was still physically unwell and emotionally distressed. "Going back to work was so heavy for me, I was so scared of the outside world. The only place I felt safe was my home." Going back to work elicited the fear of being re-infected. She only tested negative on day 60 .

Due to the hearing loss she had to consult with an audiologist, according to the ear, nose and throat specialist. Initially no one seemed to be willing to assist her until they realised the hearing loss was a possible complication of Covid-19. She perceived their assistance as disingenuous. She felt stigmatised and discriminated: "When I walked in, they were not wearing masks but they suddenly reached for masks and wore full PPE and confirmed if I was indeed negative because they can't afford to take a risk because they have children. They made me feel like the virus itself." The support from her husband and her belief in God helped her gain strength to deal with the "Covid-19 battle."

\section{Case 3: Lived Experience of the Public Service Act Employee: "I Thought the Worst was over"}

Mashudu is a 26-year old, Venda-speaking, single black African female, working as a public service act employee in government. Mashudu wrote that she was a close contact of a colleague who had tested positive for Covid-19. She admitted that they were not always wearing masks and maintaining "social distancing." What prompted her to test was the severe headache that did not respond to any medication. When Mashudu received her results, she recalled her initial reaction: "My phone suddenly felt too heavy for me, I felt my heart beating fast, I could have sworn it moved to my throat. I felt though I have a lump that would not go away I then started crying. You could never think that it could be you, but it was and I was in disbelief. Mainly because when the news initially broke about the coronavirus, we were shaken by how many people were losing their lives to it." She later experienced a loss of taste and smell, poor appetite, weight loss, excruciating headaches and insomnia. She lost hope: "I did not enjoy anything about being alive because everything was just consuming emotionally and physically." She contacted her psychologist for intervention and advice. She used to steam "Mubibiri" (schinus molle). The steaming in the Venda culture is said to heal different ailments and promotes quick recovery.

Going back to work, she felt stigmatised: "Even when you are not infectious anymore, people believed that you are. Nobody wants to come anywhere near you or your desk. It was tormenting emotionally ...." The support she received from her family, doctors, some colleagues and her belief in God was crucial.

\section{Case 4: Lived Experience of a Medical Doctor: "I was so Traumatised"}

Boitumelo is a 38-year old, Tswana-speaking, black African married female with four children. She reports having had a runny nose, and had lost both her sense of smell and taste. However, she reported a strange metallic smell and taste. She was infected in the 
line of duty. Her colleague passed away from Covid-19 complications on the same day that Boitumelo received her results. "It just hit me psychologically, I just became a patient who couldn't even get out of bed to use the bathroom; that's how sick I got. I was so traumatised."

Her husband refused to test because he was traumatised. It was difficult for them to break the news to their children. The children wanted to know if they also had Covid19 and if she was going to die and what would happen if she died. She suddenly broke down. She mentioned that her husband told her that she was sleeping all the time; she refused to bath, she did not eat and she struggled to go to the bathroom by herself, but she had no memory of this: "I don't remember any of that."

She recalled getting out of her room on day 12 . Her husband seems to have been very supportive throughout. One would question if Boitumelo had delirium symptoms for the period. The DSM-5 lists that the core features of delirium include altered consciousness, such as a decreased level of consciousness, altered attention, which can include diminished ability to focus, sustain or shift attention, impairment in other realms of cognitive function, which can manifest as disorientation and decreased memory. It relatively has a rapid onset and brief duration — usually days or weeks (Sadock, Sadock, and Ruiz 2015).

Some studies have found delirium in hospitalised patients. This could be because most studies are conducted with hospitalised patients. According to Zambrelli et al. (2020), impaired consciousness ranging from somnolence to confusion, delirium, stupor and coma has been reported in almost $15 \%$ of hospitalised patients with Coronavirus disease. Other studies indicated that $20-30 \%$ of Covid-19 patients would present with or develop delirium or mental status changes during the course of their hospitalisation, with rates of 60-70\% in cases of severe illness at all ages (O'Hanlon and Inouye 2020).

Post her isolation, she believes that her children are still in denial because they are not able to accept and acknowledge that she had tested positive for Covid-19, despite the fact that they saw her and were informed. Going back to work, she had a fear of reinfection, and subsequently she has been constantly wearing double masks (both a surgical mask and an N95 mask). She has since been experiencing hair loss.

\section{Case 5: Lived Experience of a High School Scholar: "I was Accepted by my Peers"}

Lehlohonolo is a 16-year old, Tswana-speaking, African male. He is a scholar in a boarding school in an urban area. He and his nine friends all tested positive for Covid19. This followed an identified case, but there was apparently no disinfection conducted by the school. He reported having isolated in an en-suite at home. His food was put by the door. He communicated with his family through video calls. He described himself as an introvert and the isolation had no impact on him, but he was bothered by the constant calls and at times, he chose not to answer, which led to his parents panicking. 
Tele-therapy was offered after his aunt was worried that he was not answering callsespecially from his parents. He was emotionally contained. Post isolation he returned to school and he reported to have been welcomed and supported by his peers and teachers; and everything was back to "normal."

\section{Case 6: Lived Experience of an Orthopaedic Surgeon: "I Steamed to Kill the Virus"}

Tshepo is a 50-year old, Tswana-speaking, married African male, with two children. He works as an orthopaedic surgeon in a government hospital. He got re-infected with the Coronavirus. He reported that the first time he went to test was out of curiosity because all his colleagues were testing but he was asymptomatic. He tested positive and he isolated at home for 14 days. He tested twice afterwards due to having close contacts and tested negative both times. He then lost his sense of taste and tested positive again. He was emotionally contained. However, he emphasised that he was steaming for more than an hour at a time to ensure he kills the virus: "I want this virus to regret entering my body [laughs]." He also mentioned that the steaming helps prevent breathing difficulties. He associated the steaming with his African culture (that it was something that was done in the past) and its benefits have now resurfaced in the midst of Covid19. He was surprisingly calm and reported no emotional distress.

\section{Discussion}

The above lived experiences of Covid-19 survivors depict the psychological impact and agony of being diagnosed and recovering from Covid-19. The experience heightened anxiety and trauma. Panic attacks and delirium became overwhelming mental burdens. The psychological impact seems to have dominated the physical impact. The females experienced emotional distress from the time they received the results. They were consumed by uncertainty, the fear of the unknown and a fear of death. The fear was immobilising and the rising death toll rate further induced and maintained the fear. The children also had a fear of death for their Covid-19 positive parents. The impact this might have had on the children cannot be underestimated and should not be overlooked.

The most common symptoms in line with the publicised symptoms amongst the survivors, were the persistent headache, diarrhoea, and loss of taste and smell. Of interest is that none of the participants reported high body temperature (fever). At the same time, it raises concern because most institutions are using the thermometer as a screening tool. This means that asymptomatic individuals will not be identified and could enter these institutions freely.

Female survivors also reported hair loss, which seems rare as it is not well documented and there is a scarcity of scientific research in explaining the hair loss. Laguipo (2020) reported on News Medical Life Sciences that a string of patients had reported hair loss as a complication after recovering from Coronavirus disease. We can only imagine the psychological impact of hair loss, as hair is often perceived as a woman's identity 
symbol. Some of the unique symptoms were delirium, the metallic smell and taste and hearing loss.

The males seemed to respond differently to the diagnosis compared to the females. They seemed to be emotionally contained and their focus was on their recovery process. However, the husband of one of the participants seemed to have been affected by the diagnosis. One of the husbands was also scared to test due to the fear of the unknown.

Four of the survivors were healthcare professionals, who seem to have been infected in the line of duty. This demonstrates that healthcare workers are at a high risk of infections and continuously put their lives at risk. The fear of re-infection was noted amongst them and for one of them being re-infected became a reality. Despite being infected, and despite the anxiety they experienced regarding the fear of re-infection, they still went back to work and continued to serve.

The Covid-19 outbreak has provoked associated stigma. The adolescents schooling in an urban area demonstrated that their peers were accepting of Covid-19 survivors, whereas the ones in a semi-urban area experienced stigma and discrimination from peers, teachers and the community at large. One could wonder if the stigma and discrimination were associated with the area of schooling, or could it be that some adolescents are more open minded. Almost all adults experienced stigma and discrimination. The stigma and discrimination experienced by most of the survivors can be recognised as a major challenge, which further perpetuates and maintains psychological distress.

As a way of managing some of the symptoms, most of the survivors used Traditional Medicine (TM). The World Health Organisation defines TM as the "sum total of knowledge based on the theories, beliefs and experiences indigenous to different cultures, whether explicable or not, that are used to maintain health, as well as to prevent, diagnose, improve or treat physical and mental illness" (Mothibe and Sibanda, 2019). They used herbs and trees such as Muribibi (Vhavenda) also known as schinus molle (Peruvian pepper or American pepper); Umhlonyane (Xhosa name)/Mhlonyane (Zulu name)/Lengana (Tswana and South Sotho name), also known as aretemisia afra and White Gum tree, which are traditional herbs used in different African cultures-in this case in the Vhavenda, Tswana and Zulu cultures. They did not consume them, but used these herbs to steam.

A clash between the treatment modalities was observed with one of the survivors who was discouraged from using traditional herbs by the medical doctor. This demonstrated mistrust in and criticism of TM by the medical doctor, which further instilled fear with the survivor. Moshabela, Zuma, and Gaede (2016) stated that the relationship between traditional healing and biomedical systems is characterised by mistrust, tension, and conflict, which constitutes a major setback for collaborations between the two systems. 


\section{Ramose, Sethuntsa}

However, the other three cases had merged the two systems, which demonstrated that despite the conflict, people still believe in and trust the use of their indigenous herbs.

It seems belief in God, the significant perception of social support, and psychotherapy had assisted these Covid-19 survivors to cope with the psychological impact and served as protective factors. This suggests that after receiving positive Covid-19 results patients should receive psychological support and interventions.

The information shared in this research also showed how the health system and relevant stakeholders were overburdened as the numbers of people that tested positive for Covid19 increased - they were not able to adhere to the stipulated guidelines, especially that of contact tracing. One would then wonder if this had an impact in delayed identification of infected cases or asymptomatic cases and how this could have also contributed to the continued spread of the virus. The survivors presented in these cases got infected during the peak of the first wave around June and July 2020. Mkhize (2020b), in his media report released on 28 June 2020, stated that the spread of Covid-19 in "South Africa" had picked up significantly, as there had been 7210 new recorded cases within a 24hour period.

\section{Conclusion}

We have described Covid-19 as the source of the fear of the unknown. This fear manifested with the research participants in various ways, such as the avoidance of those already infected by the virus or those who had been affected but had subsequently regained their health. By drawing contrasts and comparison between the Black Death and Covid-19, we have highlighted the ethical imperative to combine the "social distance" prescribed by Covid-19 with ethical proximity to the other. We have also shown the danger of dogmatism and pointed to planetary thinking as a means to move towards the cognitive and ethical revolutions. The case studies discussed show either remoteness or proximity to open-mindedness as the appropriate scientific attitude at odds with dogmatism, which precludes and pre-empts both the scientific cognitive and the ethical revolutions. Dogmatism is the rehearsal of the Black Death as well as the irrational plunging of humanity into the Black Death through the wilful pursuit of an idle death wish.

\section{References}

Cantor, N. F. 2002. The Black Death and the World it Made (Pocket Books). London: Simon and Shuster.

Carvalho, P. M. M., M. M. Moreira, M. N. A. de Oliveira et.al. 2020. “The Psychiatric Impact of the Novel Coronavirus Outbreak." Psychiatry Res, 286. Accessed August 30, 2020. https://doi.org/10.1016/jpsycres.2020.112902.

Collier, P. 2008. The Bottom Billion: Why the Poorest Countries are Falling and what Can Be Done About it. New York: Oxford University Press. 
Congregation of the Sacred Hearts. (n.a.). Sint-Antoniusberg 11, Leuven, Belgium. Paragraph 6.

Dubey, S., P. Biswas, R. Gosh, et.al. 2020. "Psychosocial Impact of Covid-19-19.” Diabetes and Metabolic Syndrome: Clinical Research and Reviews (14): 779-788. https://doi.org/10.1016/j.dsx.2020.05.035.

Fan, H., R. F. Conner, and L. P. Villarreal. 1994. The Biology of AIDS. London: Jones and Bartlett.

Laguipo, A. B. B. 2020. "Recovered Covid-19 Patients Report Hair Loss Months after Infection.” News Medical Life Sciences. Accessed August 30, 2020. https://www.newsmedical.net.

Langer, W. L. 1975. The Black Death, in Readings from Scientific American Biological Anthropology. San Francisco: Freeman and Company.

MacDonald, T. H. 2005. Third World Health Hostage to First World Wealth. Oxford: Radcliffe.

Mkhize, Z. 2020. Media release. Accessed August 29, 2020 @DrZweliMkhize.

Mkhize, Z. 2020. "Health Minister Dr Zweli Mkhize Updates on Covid-19 Situation” (SABC News). Accessed June 30, 2020. www.sacoronavirus.co.za .

Moshabela, M., T. Zuma, and B. Gaede. 2016. Bridging the Gap between Biomedical and Traditional Health Practitioners in South Africa. Accessed August 30, 2020. https://www.hst.org.za.

Mothibe, M. E., and M. Sibanda. 2019. “African Traditional Medicine: South African Perspective, Traditional Medicine and Complementary Medicine." Accessed August 28, 2020. https://www.intechopen.com.

National Institute for Communicable Disease. 2020. “Coronavirus Disease 2010 (Covid-19) Caused by a Novel Coronavirus (SARS-CoV-2): Guidelines for Case-finding, Diagnosis, and Public Health Response in South Africa."

New Scientist. 1987. “AIDS Truce Brings History to a Halt.” April 9, (21). In Hegel's Twilight: Liber Amicorum Discipulorumque Pro Heinz Kimmerle, edited by M. B. Ramose. 2013. Rodopi Publishers.

O’Hanlon, S., and S. K. Inouye. 2020. "Delirium: A Missing Piece in the Covid-19 Pandemic Puzzle." Age and Aging. Accessed August 30, 2020. www.ncbi.nlm.nih.gov. https://doi.org/10.1093/ageing/afaa094.

Palca, J. 1987. "Settlement on AIDS finally Reached between US and Pasteur.” Nature 326 (6113): 533. https://doi.org/10.1038/326533a0. 
Pope Francis. 2013. Apostolic Exhortation Evangelii Gaudium of the Holy Father Francis, Vatican Press, Vatican 2013, paragraph 59.

Sadock, B. J., Sadock, V. A., and Ruiz, P. 2015. Kaplan and Sadock's Synopsis of Psychiatry: Behavioural Science / Clinical Psychiatry. 11th edition. Philadelphia: Wolters Kluwer.

Shea, M. 2018. Aquinas n God-Sanctioned Stealing. American Catholic Philosophical Quartely 92 (2): 277-293. https://doi.org/10.5840/acpq201831146.

Troyer, E. A., Kohn, J. N., and Hong, S. 2020. “Are we Facing a Crashing Wave of Neuropsychiatric Sequelae of Covid-19? Neuropsychiatric Symptoms and Potential Immunologic Mechanisms.” Brain, Behaviour, and Immunity Jul 87: 34-39. https://doi.org/10.1016/j.bbi.2020.04.027. Epub 2020 Apr 13.

Wahbah, M. (ed). 1984. Roots of Dogmatism: Proceedings of the Fourth International Philosophy Conference, 23-26 October 1982. The Anglo-Egyptian Bookshop.

Zambrelli, E., Canevini, M., Gambini, O., and D’Agostino, A. 2020. Delirium and Sleep Disturbances in Covid-19: A Possible Role for Melatonin in Hospitalized Patients? Sleep Medicine (70): 111. Accessed August 30, 2020. www.elsevier.com/locate/sleep. https://doi.org/10.1016/j.sleep.2020.04.006. 